\title{
Thinking Comparative Engineering Education: India and the Rest
}

\author{
Rajarshi Roy \\ National Institute of Technical Teachers' Training \\ and Research (NITTTR), Kolkata \\ [Under Ministry of Human Resource Development, Government of India] \\ Block -FC. Sector-III, Salt Lake City, Kolkata-700 106, India. \\ E-mail: dr_r_roy@yahoo.com
}

\begin{abstract}
Engineering education in the globalized perspective undergoing metamorphic changes in changing paradigms. In the context, as a developing nation, India has an opportunity to share the experience of the advanced nations and thereby, through juxtaposition, can adopt appropriate policies for strengthening the existing system of engineering education, best suits for national situations. Perception about the profession and problem context of engineering education needs ramification. Shortcomings in engineering practice need to be identified in the areas of innovation, research and development, design and technical improvisation. System related and profession oriented issues need to be addressed through the global experiences. Contrasting values of employer organizations and profession for an engineer need a clear synthesis for the development in different perception-context. The paper present a snap views on the stated issues which believed to be contributing factors for strengthening the Indian engineering education.
\end{abstract}

Index Words: Engineering Education, KSA, Pedagogy, Profession, Workplacediscourses, Organizational Values, Professional Values.

'Existing educational institutions were created to meet the need of a society that is first disappearing. We need new educational organizations that can exploit the new technologies to meet the need of twenty-first century. Economic development will depend as much on the success of creativity and supporting such organizations, as on establishing the technological infrastructure. It is critical to get this right because those countries that harness the power of multimedia communication for education and training purposes will be the economic powerhouses of twenty-first century. The development of modern communications and information technologies is becoming a major instrument for widening access to education and training on a cost-effective basis while also enhancing its quality.'

Issues and Ideas
in Education
Vol. 1, No. 1
March 2013
pp. $87-107$

Tony Bates

\section{INTRODUCTION}

Engineering Education in Indian context is yet to be defined (Tilak, 2001). As apparent, the terminology 'Technical Education' is more a phenomenon of imposition over the past-colonial nations by UNO through its sister concern,

\section{CHITKARA 司} UNIVERSITY

C 2013 by Chitkara University. All Rights Reserved. 
Roy, R.

UNIVOC. However, for convenience, it may be assume that 'Engineering Education'is the activity of teaching engineering and technology, at school, college and/or university levels. The generalized goal of engineering education irrespective of levels is to prepare people to practice engineering as a profession and also to spread technological literacy, increase student's interest in technical vis-à-vis technological careers through science and mathematical education, accompanied with hands-on-learning. Engineering education often begins with technology education in schools and is continued at college and university. (Douglas, Iverson \& Kalyandurg, 2004). As like performing arts, it is more akin to psychomotor domain of learning apart from cognitive and affective domain.

The arena of engineering education has been, since independence, a subject of scrutiny. Changes brought about various government and industry based inquiries and studies into engineering education have often proved to be too little and often inappropriate. In many ways studies into engineering education have resulted in producing many educational benchmarks and yet not addressing issues of dissatisfaction with engineering graduates' core attributes.

Issues of professional engineering education are not unique and many of these are found in the education of other professions (Aulich, 1990). It seems to be the nature of the best of professional education as a whole since pedagogy of professions and epistemology of professions are generally multidisciplinary in nature and, among professions, the engineering profession is the most in multidisciplinary of all.

The present exponential rate of change in society has drastically lowered predictability and increased uncertainties. It is to be agreed that social change contributes a cultural lag between technological development and social change ${ }^{1}$. It will be accepted by almost each and every hand that future is neither an extrapolation of the present and nor of the past. Under these circumstances, avoiding mistakes is as important as being innovative. Science and technology as well as engineering have a symbiotic relationship. But science is preoccupied with understanding and explaining, while engineering is concerned with doing, realizing and implementing. Therefore, the aim of future engineering education aught to be integration of knowledge, sequel of skill, understanding and experience. Now a days there is a prediction in context of Indian Engineering Education that Space, Computer, Energy and Communication will be the main technology drivers in the present era, with Materials Science and Engineering qualifying as the underpinning technology.

Recognition and strategic role that engineering profession play in the economy and public welfare has ensured that the profession and its formation 
has been subject of public scrutiny. In the globalized culture, to be more frank, in the present One-World-Culture, which is a resultant of LiberalizationPrivatization-Globalization (LPG), Engineering-Education in a 'developing nation' can't (and should not) be left in isolation. However here also domination is prominent from the 'so-called' bourgeoisies' counters. Professor Richard Morrow (1994), the past chairman of the National Academy of Engineering in the United States referring to the strategic value of engineering professions to US national economic and social welfare, commented, the nation with the best engineering talent is in possession of the core ingredient of comparative economic and industrial advantage. One is to note here that engineering education in United States possess a grand contribution through 'brain-gain' policy ${ }^{2}$.

The Royal Society of the Arts (Weingart, 1978) had raised the problems of the relevance of engineering education way back in 1853. Major national inquiries and reviews by Mann (1919,), Grinter (1955), Augustine (1994), Dowell (1998) in the United States, Finniston (1980) in Britain, Moorehouse (1964), Williams (1988), Johnson (1996) in Australia and Banerjee and Muley(2007) in India have ensured that educational issues in professional engineering stayed in the spotlight in their nation. The issues of engineering education were time invariant. Engineering graduates were seen to be lacking the attributes, skills and knowledge necessary for a high level of innovation, and for the management of technology and human resources in the production of goods and services, as well as the entrepreneurial skills necessary in the commercial world.

A survey conducted in Australia to determine employers' perception towards engineering graduates from Australian universities revealed that 97\% of employers felt that engineering graduates from Australian universities lacked an adequate knowledge and skill base to meet the future needs of the engineering workforce (Johnson 1996). Both the Finniston Inquiry in Britain and the Williams Review in Australia linked the deficiencies and inadequacies of engineering practice to engineering education. Shortcomings in engineering practice were identified in the areas of innovation, research and development $(R \& D)$, design and technical improvisation.

Many of the recommendations of the studies and reviews for improving engineering education were, to some degree, implemented but that did not address the divergence between professional engineering practice and education. Computer and information technology revolution was incorporated into engineering curricula and provided new tools for greater and quicker access to data bases, greater exactitude in engineering analysis and design, and widened the audience with whom the engineer communicated in work sphere. 
Roy, R. 90

Yet, despite these new tools, educational issues in engineering remained and, if anything, the introduction of computer and information technology further consolidated the technical dimension of the engineering curricula too.

The point is that the changes in engineering education are either too slow or are of the wrong kind to address the workplace and social demands of engineering graduates, in contrast of a higher degree of change and advancement of technology. These issues are part of overall problems facing engineering education in today's LPG influenced world. Prominent and more pronounced among those are:

1. Engineering curricula in most of the universities across globe are excessively positivist in character and generally ignores social, political, environmental and economic dimension of professional engineering work;

2. Rigid entrance requirements into quality engineering courses. Entry into engineering courses in India requires passes in physical sciences and mathematics in the final year of higher secondary schooling. These requirements exclude the majority of higher secondary passed students from engineering education;

3. Exploration of aptitude over different branches of engineering studies has not yet been considered as criteria for selection of students at the entrance level.

4. Mismatch of the $\mathrm{KSA}$ (knowledge, skill and attitude) of engineering graduates and the type of knowledge, skill and attitude needed in the workplace;

5. Further followed by inappropriate (and often absence of) pedagogy of engineering education that may best suit the national educational atmosphere ${ }^{3}$.

6. Engineering education (and therefore profession) does not present an attractive option to the outstanding students now a day due to mushrooming growth of institutions, ignoring required manpower-planning, which is prominent from some studies (Roy, et. al, 2006) that reveal that per capita income potentiality of newly graduate engineers has drastically fallen down compared to those graduated even a decade ago.

7. Relatively high attrition rates of students undertaking engineering courses at institutes, dually affiliated by Indian (and in general, national) and foreign universities.

8. Prominent existence of gender imbalance slanted towards boys among engineering students. Gender imbalance in the engineering profession makes the discipline less attractive to prospective female students; even 
less than $5 \%$ of the engineering intake into Indian schools and faculties of engineering are women (Selected Educational Statistics, MHRD, 2008);

9. Inappropriate academic recruitment. Academics into engineering institutes and faculties are generally recruited on the basis of their discipline oriented research degrees and research practice and such practice seems to downplay the application oriented nature of the profession.

\section{PROBLEMS}

There are two main problems facing the engineering profession in India (and elsewhere) as far as professional education is concerned. One problem relates to the skill, knowledge and attitude acquired during the period of formal professional engineering education, and have been found wanting to meet the demands of the workplace.

Another problem relates to perceptions of the engineering profession, which has translated into a lack of attractiveness of engineering as a course of study, as evidenced by the long tail of entrants into engineering courses with relatively poor academic preparation and abilities, and the gender imbalance that exists within the profession.

Woolnough (1994) showed that in Britain the rate of growth in engineering enrolments has not kept up with the expanding sector of higher education, in contrast to Indian scenario. The increased industry demand for professional engineers in Britain has been accompanied by a relative decline in enrolment in engineering courses. Department of Education and Employment [DfEE] (2000) estimated that the annual growth in professional engineering jobs in Britain for the period 1998-2009 is in excess of 2\% per annum. Taking into account professional engineers leaving or retiring from professional work, it would necessitate a growth of enrolment in engineering close to 5\% per annum. This has led Richard Wilson (2005) to comment that the increasing demand for professional engineers in Britain cannot be met. On the other hand, no such specific study has yet been reported or conducted to estimate future manpower requirement in Indian socioeconomic setup ${ }^{4}$. Huband (2007) points out to the decline in relative engineering enrolments in the United States. Since 1965 the decline in engineering enrolment in the United States has been observed to be less than $3 \%$ of the total higher education enrolment. This has led to almost a critical shortfall in supply of professional engineers in the United States (Hutchinson et al, National Science Foundation 2004).

On contrary, the juxtaposition reveals that in selected specific trade, Indian engineering education system is producing excess than the required manpower, which acts as an underpinning reason of declining per-capita income of the 
Roy, R.

engineers in specified branches. It is also evident that pyramidic structure of engineering education transformed into inverse-pyramid, where degree-level engineers are even (little) more in number than the diploma-level engineers. This leads to a situation where graduate and post-graduate engineers are snatching the job meant for diploma- hordes and diploma-holders, quite naturally, forced to occupy the positions of technical manpower, meant for certificate-level engineers.

The enrolment in engineering courses has fallen by $40 \%$ in Denmark 92 (Ellis, 1991), 35 percent in Switzerland, and $10 \%$ in the Netherlands and Norway (Thulstrup, 1999). Though the rate of annual growth in engineering enrolment in Australia over the period 1983-2004 was 4.3\%, it lagged behind the overall growth in enrolments at higher education institutions for the same period. The overall growth in Higher Education enrolments in Australia was 5.6\% with disciplines such as Business and Economics, Law, and Science registering annual growths in enrolment, of 7.0\%, $8.0 \%$ and $5.6 \%$ respectively (Department of Education, Training and Youth Affairs, 2005). There is a definite trend of people entering higher education who in growing proportion disregard engineering as an attractive option for study in the developed countries. In contrast, being developed country, India is experiencing an increasing trend both in quantitative growth of Institution and enrolment too.

The relative lack of attractiveness of engineering as courses of study is not new. This has been identified in Australia since 1950's onwards by, among others, Moorhouse (1964), Williams (1988) and Johnson (1996). Though the entry scores into engineering courses at the more prestigious universities such as Sydney, Melbourne, Monash, New South Wales and Queensland are high, they are lower than the entry scores to other professional courses such as medicine and law at these universities.

This goes in consonance with GRE score of the entrants of IITs and nonIIT engineering Institutes.

There is also a long tail of students with relatively poor academic achievements entering engineering courses at the less prestigious universities (US Department of Education, Training and Youth Affairs, 2005). The minimum score for entry into engineering courses at the Victoria University, for instance, would not meet entry requirements for any courses at the abovementioned universities.

Thus there seems to be, as far as the engineering profession is concerned, issues concerning both sides of the professional engineering educational spectrum. Lack of attractiveness of engineering as a course of study has ramifications on the status of the profession with a visible synergism between these two factors. It is difficult to disengage the standing of the engineering 
profession from engineering education. It is not clear whether it is engineering education that fails to attract a client group because of the standing of the engineering profession, or whether the poor standing of the engineering profession is the result of the lack of attractiveness of engineering education. The exit part of professional engineering education does not, seemingly, meet needs of professional engineering work. The problem therefore needs to be attributed to the professional engineering education and assumptions on which the design and implementation of engineering curriculum is based.
Thinking Comparative Engineering Education: India and the Rest

\section{PEDAGOGIC ISSUES}

A study in the USA has concluded that 'the nation's competitiveness depends, in part, on the skills of tomorrow's engineers'. In fact, some universities in the USA, such as, Brown University and MIT, have established themselves as corporations. Excellence, quality, relevance, customer satisfaction, service, etc., have become the buzzwords in the engineering institutions of the West. Some impediments to change have been identified as science-heavy studies, narrow specialization, and inability to work at interfaces between traditional disciplines and lack of team approach to engineering. Add to this the following projection.

In 1975 the world population was 4 billion. Of these, 34\% lived in an urban environment; 0.8 billion in the cities of the developing world and 0.73 billion in the cities of the developed world. It has been projected that by 2025 the world population will be 8.29 billion. Of these, $61 \%$ will be living in the urban environments; 4.03 billion in the urban sprawls of the developing world and 1.04 billion in the cities of the developed countries. Infrastructure development will be a major problem. Thus, the centrality of technological solutions is inevitable.

Globalization has brought in its wake an emphasis on consumer concerns, e.g., quality (quality assurance, need for continuous upgradation of quality at reduced cost), cost and variety. In view of the enormous skilled manpower, India may become a significant production center of the world. Economic restructuring heavily depends on the performance of technology driven industrial and services sectors. For competitiveness adoption and adaptation of modern technologies and managing them with advanced managerial tools are essential. This has placed significantly increased demands on technical manpower than has been the case so far.

At a time when technical competence of the highest quality is called for, the new economic policy regards expenditure on engineering (higher) education as less of an investment of the nation in the future and more of a subsidy to a 
relatively affluent section of society ('unmerited subsidy'). This has created a need for private resources and a new species of 'businessmen as providers of technical education' has emerged. Thus the development of excellence in the profession is no longer a central societal goal.

In this changed paradigm, engineering education has to be restructured. The need to teach science in engineering schools has been grossly inflated by the needs of the engineering profession for esoteric knowledge and of engineering educator for academic respectability (Beder, 2006). In Indian 94 scene, with consonance of booming IT market, it is prominent that engineering education has become a second rate science education resembling more an applied physics course and completely devoid of its characteristic features and identity. Most of who design engineering curricula are far removed from engineering as it is practiced even a decade ago ${ }^{5}$.

Engineering activity, like the other great profession of Medicine, is prescriptive in nature and in its practice, diverse skill are required, e.g., a capacity to work in overlapping areas between disciplines and a flair for selflearning new skills. An engineer of the future has to emerge as a creative problem solver. Mere analytical skills are not enough. An 'engineering design' integrates mathematics, basic sciences, engineering sciences and complementary studies in developing elements, systems and processes to meet specific needs. It is a creative, iterative, open-ended process subject to constraints, which may be governed by standards or legislation to varying degrees depending upon the discipline. These constraints may relate to economic, health, safety, and environmental, social or other pertinent factors. Thus, the 'neat and rigorous' solution obtainable in pure science is mostly unattainable in engineering.

Other areas aliens to courses in pure science are computer-assisted simulation, similitude, and techniques of engineering approximations, multicriteria decision-making, and basics of business, professional ethics and laws pertaining to intellectual property rights.

Delivering a viable, self-sustaining technical culture is also of the essence. The example of the former USSR that produced the most narrowly trained specialist technologists is a case in point. In spite of the technical brilliance, a lack of user-friendliness in products and the absence of safety and ecological concerns characterized the system. Therefore, unlike pure science, where pursuit of knowledge for its own sake is permissible, engineering education and, as a corollary, research has to be based in relevance.

The shortcomings in professional engineering in Australia, practice have been widely identified and documented. Dowell, E., Baum, E., \& McTague, J. (1998), Williams (1988), Johnson (1996), Beswick, D., Julian, J., and Macmillan, C. (1988), as well as Bothwick, S., and Murphy, T.(1998)'s studies 
undertaken to establish the relationship between the knowledge derived from engineering education and the knowledge applied in professional work have shown a divergence between the worlds of professional education and professional work. Possibly India need to reframe its future plan of action in context of engineering education from the countries ahead of us in terms of developmental impacts and economic stability.

Key conclusions and recommendations proposed by the Williams Committee, in the 1980's, called for changes in contemporary engineering education, across globe. These were based on the identification of contemporary demands on professional engineering practice. Some of those were:

(a) Technology has technical and human aspects. The nations undergoing the greatest rate of technological change have an understanding of the human aspects of technology. There were many employers who did not appreciate the dual nature of technological change: this was also true of many practicing engineers;

(b) The attrition rate of engineering students enrolled in engineering degree courses was relatively high in comparison to students enrolled in other professional courses;

(c) Engineering schools and faculties were more responsive to the changes and demands in engineering science and the equipment associated with engineering science than to changes in engineering practice. Too little emphasis was placed, in engineering curricula and research, on the human aspects of technology; and

(d) Engineering schools and faculties in India are lacking innovation in designing and introducing unconventional programs in engineering curricula.

Among the many recommendations put forward by the Williams Committee of Australia, the most relevant were concerned with engineering curricula at Australian universities. These recommendations called for the development of appropriate engineering curricula to meet the needs of engineering practice. The report also identified the need for change in the organizational structures of engineering schools, colleges and faculties in order that such recommendations could be accepted and implemented. The recommendations suggested that:

(i) Engineering students needed greater exposure to the art of technology rather than the current emphasis on the science of technology;

(ii) Engineering curricula needed to pay greater attention to professional and social communication skills, and management and basics of economics; 
Roy, R.

96

(iii) Engineering curricula needed to evolve as part of a business context;

(iv) Engineering academic staff members needed to develop closer links with the employers of engineers in order to ascertain organizational engineering demands and to evaluate how these demands connect to current engineering education prevailing in Australia;

(v) Engineering research at universities ought to take the path of multidisciplinary group research. This would reflect the true multi-variant nature of engineering; and

(vi) Engineering education needed to be expanded to meet the expected demand for graduate engineers. It was suggested that an annual growth of $3 \%$ of engineering graduates would be the bare minimum to sustain engineering activity in Australia. Such expansion had to be accompanied by a $14 \%$ increase in investment in staff, spatial resources, and equipment.

A survey done by Vollmer in Germany, of 1200 graduates in mechanical engineering showed that engineering education contributed $50 \%$ of the knowledge of engineering sciences required to perform well in a job, and only $2 \%$ of the non-technical skills required in engineering practice (Muller, H.D. \& Collet, M. 1995). The same German study also showed that $48 \%$ of mechanical engineering graduates worked initially in production- related areas and $24 \%$ worked in research and development. Five years after graduation only 14\% of mechanical engineers worked in the production-related areas and $4 \%$ of mechanical engineers worked in the area of research and development. There is an evident diffusion of professional engineers from the technical areas. A study of employers, in Britain, disclosed dissatisfaction with cognitive skills and knowledge British graduates developed in the course of their engineering studies (Glover, I.A. \& Herriot, P., 1982). The Finniston Inquiry, earlier, revealed the following attitudes and opinions:

- The employers had great difficulties in recruiting the appropriate engineering graduates suitable for the areas of production.

- There were however no such difficulties in recruiting suitable engineering graduates for research and development;

- Engineering graduates tended to be less ambitious than graduates from other professional fields such as law, business and accountancy. Engineers were therefore less likely to be promoted within an organization and were therefore more exposed to the vagaries of the market and more likely to be retrenched during economic downturns, and

- The relatively high unemployment of engineers in comparison to the other professions would be to the detriment of the professional engineer's status, 
and would influence the quality and quantity of intake into engineering courses (Wilenski, H., 1964).

A similar study was undertaken in Australia to establish the relationship between the cognitive skills derived from professional engineering education and the nature of professional work. Private firms and government organizations at commonwealth, state and municipal levels were surveyed and the results of these surveys showed that the employers were generally satisfied with the knowledge engineering graduates possessed in the areas of basic sciences, engineering sciences and disciplinary technical engineering practice (Bothwick $\&$ Murphy, 1998). Concerns were expressed at the lack of the following attributes among engineering graduates:

- Knowledge of industrial relations and management of people;

- Knowledge of management of costs and resources;

- Knowledge of engineering as part of the broader business context; and

- Skills in written and oral communication.

German, British and Australian studies observed a mismatch between the knowledge imparted in professional education and in engineering practice.

\section{WORKPLACE DISCOURSES VIS-À-VIS VALUES}

Like any professional education, the education program for professional engineers must be designed with the view to meet both the demands and needs of professional workplace and the social identity and a culture of the engineering profession. These needs often conflict since employer needs and demands are directed towards profits and a professional identity is embedded in service not only to employers but also to the community, environment and social well-being.

As a largely an employee profession there are tensions often associated with the difference between professional and employer values. This is a particular issue for professional engineering education providers who see themselves as fostering, through education, professional values.

Employers have a strategic stake in the professions because the growth of business and profitability is dependent on the competence and integration of its professional workforce into their organizations. To many employers, the professions represent a highly educated and skilled workforce, but are still a part of the employee population. The integration of professions into organizational missions and objectives cannot be complete if the professional occupation retains a strong identification with professional values and identity. 
A structural conflict of values exists between organizational values, which are directly driven by the economic imperatives, and professional commitments that are based on notions of service, welfare and safety. These conflicting values lead to tensions in the workplace, which may be overt but are more often implicit in workplace relationships. Beder (1989) observed four major areas of tension for professional engineers employed in organizations as the result of differences in values between professional engineers and the employing organizations. She framed these areas of conflict in terms of goals, incentives, control of work and influence over outcomes. This is shown in Table 1.

Table 1: Contrasting values of employer organizations and professions

\begin{tabular}{|l|l|l|}
\hline $\begin{array}{l}\text { Contrasting } \\
\text { values } \rightarrow\end{array}$ & \multicolumn{1}{|c|}{ Organizational Values } & \multicolumn{1}{c|}{ Professional Values } \\
\hline Goals & $\begin{array}{l}\text { Developing products and } \\
\text { services for the markets }\end{array}$ & $\begin{array}{l}\text { Maintaining standards of } \\
\text { technical competence }\end{array}$ \\
\hline Control & $\begin{array}{l}\text { Generally hierarchical, values } \\
\text { are asserted and developed at the } \\
\text { higher echelons of organizations }\end{array}$ & $\begin{array}{l}\text { Generally organized along } \\
\text { collegial lines. Professions tend } \\
\text { to represent democratic culture. }\end{array}$ \\
\hline Incentive & $\begin{array}{l}\text { Pay rises and promotion through } \\
\text { organizational ranks }\end{array}$ & $\begin{array}{l}\text { Collegial recognition and } \\
\text { acclamation. }\end{array}$ \\
\hline Influence & $\begin{array}{l}\text { Official position within the } \\
\text { organization. }\end{array}$ & $\begin{array}{l}\text { Recognition of expertise } \\
\text { and possession of special } \\
\text { knowledge and skill base. }\end{array}$ \\
\hline
\end{tabular}

In reality, professional discourses in employer organizations often tend to be subjected to organisational objectives. This is most commonly the case in the engineering profession where organizations serve as infrastructures to professional engineers. In such cases professional engineers are assimilated into organisational ways of working and entrepreneurship. Where this occurs, engineering professionals become locked into the employer organizational structure to the extent that individual professional engineers derive their status from the employing organization. In such cases professional accountability in engineering tends to take on secondary importance to careers and organizational matters. The process in which organizational values predominate over professional values is not just one of assimilation, but a kind protective selfinterest, which is focused on shaping the infrastructure in ways that support professional practice.

An American study (Zussman, 1985) of the role professional engineers play in employer organizations, showed that professional engineers employed 
in enterprises and organizations were more concerned with organizational than professional values and objectives. This study complemented an earlier study, which suggested that the ideas and values of professional engineering discourse in the workplace were being shed (Prandy, 1965). In this earlier study, Prandy (1965) observed that professional engineers in Britain were more sensitive to the needs and demands of their employers than their career and professional engineering issues. They were more concerned with the possibility of being dismissed by their employers than being expelled from professional associations.

In the United States, professional engineers also exhibited a greater sense of loyalty to their employers than to their profession, though not necessarily out of fear of consequences. Engineers were generally unconcerned about the opinions of other members of their profession who were outside their organization and they gave overriding precedence to company profits over notions of professional commitments (Goss, 1969). This can be contrasted with the more autonomous professions, such as law and medicine, where collegial accountability is still observed. There was greater work satisfaction among professional workers employed in organizations when the professional discourse retained a commitment to professional ideals and values, especially in relation to work autonomy. Wilenski (1964) in his study of professional work found that the greatest work-dissatisfaction among the professional workforce was found among professional engineers where they had little participatory role in decision-making process concerning their work. Participation in decisionmaking has been shown to be an important component in work satisfaction for professions embedded in organizations (McGregor, 1960).

Larson (1979) suggests that the commitment of employing-organizations and bureaucracies to rational processes entrapped engineers, and blended engineers and bureaucratic rationality in ways that worked against the engineering profession. This close identification with bureaucracies provides individual engineers with high bureaucratic status within an organization but at the expense of the profession as a collective, of its professional autonomy and its control over professional markets. For the engineering profession, its continuous links with employing organizations and their bureaucracies has led to a synergy of entrapment. This organizational framework acts as a medium for professional engineering discourse. It has important epistemic implications for the discourses of professional engineering education. This 'capturing of the engineering profession by discourses of business' means that workplaces' knowledge practices (such as knowledge of organizational behaviour) constitute a substantial portion of professional engineering discourse (Goldman, 1991). If this diversified and blended knowledge base in engineering is to inform

\section{Thinking Comparative Engineering Education: India and the Rest}


Roy, R.

the preparation of young engineers, there is a need for the incorporation of subjects that deal with management and organizational behaviour as a part of the engineering curricula.

\section{Engineering Profession Verses Engineering Education}

The attractiveness of the engineering profession is governed by how the prospective entrants perceive engineering as a profession and as a course of study. Albert Einstein perceived engineering to belong to the logical empiricist philosophy, which eschewed free inventions from human intellect and relied strictly on empiricism (Howard, 2005).

The engineering profession has had a relatively poor status and this view has been carried into the self-perception of members of the engineering professions. In the mid sixties, during the most intense time of the cold war period in the United States, when there was a strong empathy with science and technology in the belief that these could address human, economic and political issues, the engineering profession did not have a high professional profile in the community. Professional engineers were more likely to be valued on the basis of their expertise rather than as members of a profession. In a study of occupations and professions Wilenski (1964) found that professional engineers had also negative perceptions of themselves. He called the engineering profession an 'alienated profession'. Amongst the professions surveyed, professional engineers exhibited the highest dissatisfaction with their occupation, though not with their work (McGregor, 1960). These selfperceptions of engineers were widespread across the fields of employment of professional engineers: in industry, engineering consulting firms and academic departments at universities. The engineering profession, in comparison to other professions, had relatively low self-esteem. American surveys conducted by the National Academy of Engineering showed that the engineering profession lacked identity, and that many people could not distinguish between engineers, technicians and scientists (Ahlstrom, 1982). Braham (1992) in his study of the attractiveness of engineering as a course of study among the young mentions an American surveys of public attitudes towards professional engineers, which shows the low esteem in which the public holds professional engineers. Engineers were perceived as having poor social skills, being self-absorbed, loners and rigid in mind. Hilton and Lees (1988) place the blame on the lack of appreciation of the engineering profession on the poor marketing of the profession. Engineers were isolated from the mainstream of the society because they were associated with engineering failures, the nature of engineering work being such that failures could not be associated with particular persons and the blame shifted to the profession. 
In terms of public perceptions, the engineering profession in Australia has not marketed itself well. Yates (2000), in a discussion paper on the status of engineers in Australia, noted that professional engineers have failed to market themselves as a profession and are responsible for much of the perception as an alienated technical and scientific occupation that is sometimes associated with technical trades. Beder (1989) using a survey conducted in 1992 by the Institution of Engineers of Australia points to the amorphous nature of the engineering profession in Australia. Australian public could not distinguish between the activities of different engineering disciplines. This was borne out by subsequent surveys conducted by I.E. Aust., which showed that beyond the construction of machines and buildings, the Australian public had little knowledge and appreciation of what engineers did (Diedrich, 1996\&2000). The public profile of the engineering profession in Australia is illustrated in Table 2. These perceptions of engineering are somewhat contradictory and reflect uncertainty concerning the nature of the engineering profession. The positive perceptions of translating ideas into reality and coping well with weighty responsibilities are not congruent with the negative perceptions of engineers as being too theoretical and not senior management material.

Table 2: Perceptions of the engineering profession

\begin{tabular}{|l|l|}
\hline Positive Perceptions & Negative Perceptions \\
\hline Capacity of trustworthiness & Conservative, pedantic and aloof \\
\hline $\begin{array}{l}\text { Capacity to cope well with weighty } \\
\text { responsibility }\end{array}$ & $\begin{array}{l}\text { Too theoretical, lacks practical } \\
\text { skills }\end{array}$ \\
\hline Capacity to translates ideas into reality & $\begin{array}{l}\text { Tends towards rigid, outdated } \\
\text { management style }\end{array}$ \\
\hline $\begin{array}{l}\text { Capacity to represent a source of ideas and } \\
\text { technologies }\end{array}$ & $\begin{array}{l}\text { Capacity to act as a bridge between } \\
\text { management and workers }\end{array}$ \\
\hline $\begin{array}{l}\text { Inclination to keep government and big } \\
\text { business honest }\end{array}$ & Not senior management material \\
\hline
\end{tabular}

The alienation of the engineering profession was also evident among engineering undergraduates. In this case, however, the dissatisfaction had little to do with the engineering curriculum and education, but rather with ignorance concerning the final destination of engineering graduates.

A study done by Shulman (2005), a member of the Carnegie Foundation for the Advancement of Teaching, on perceptions of professional engineers
Comparative

Engineering

Education: India and the Rest 
Roy, R.

among students to a question of 'what is an engineer?' produced a response ... An Engineer is someone who uses math and science to mess with the world by designing and making things that other folks can use (pause)...'And once you mess with the world, you're responsible for the mess you made. A survey in Britain, by Industry Ventures, of 2700 final year engineering undergraduates, showed that the majority of students had no idea what engineers did. An earlier study conducted in the United States showed that the majority of engineering students had only vague notions of engineering work (Ritti, 1971).

The motives for studying engineering were not clear in the survey of engineering students in a study Durcholz (1979) performed in the United States. As a result of his study Peter Durcholz commented: As I continued to interview students, it was clear they were puzzled about what their chosen career would lead them to in the way of work. Hutton and Gerstl (1995) in an inquiry into why students in the United States chose engineering as their discipline of study, found that a third of the students chose engineering due to the influence of a role model. A quarter of the students undertook engineering studies because they saw engineering as a path to management and a further third of the students studied engineering because they felt they had a technical disposition and mechanical aptitude. Interestingly, Hutton and Gerstl observed that student perceptions of engineering did not show common themes, reflecting a general confusion about the nature of engineering work. Skobrook (2006) commented that students' preconceptions of engineering and engineering studies in Britain were not matched by the reality.

Perceptions of engineering professions manifest confusion because of the multi-variant discourses of professional practices.

Possibly the perception of engineering students would not be much different from the experience of the west. Therefore intending students of engineering education need to be well informed about the purpose of engineering education first, prior to take-up the study; and the task stands to the engineering educators to inform the students about the purpose of this very gamut of education. Rigorous studies centering round the system of engineering education need to be taken up to explore the real situation. Unfortunately the domain is still neglected, causing an adverse impact over the policy formulation in engineering education.

\section{POST SCRIPT}

As reflected from the present scenario, what actually happening is the technology revolution and globalization is creating a network. This network is the mode of creation and diffusion of technology. In the networking- 
paradigm, national policies still coming on the way. Even the poorest countries also need to implement policies, which encourage research, development and innovation, access and development of advanced skills through engineering education. It is national policy, not the national charity, which will determine whether new technologies are really becoming tool for human development everywhere or not. Also how, the social atoms perceive their responsibilities in dealing with the profession. Commitments under Trade Related aspects of Intellectual Property Rights (TRIPS) of World Tread Organization (WTO), to promote technology-transfer to developing countries are appearing as mere paper-promises, and are often neglected in implementation. The basic form of development is 'creativity' which generates the potentialities of technocapabilities, harnessed with emotional and thereby social intelligence. The ultimate significance of the present networking (between globalization and technology) age is that it can empower people by enabling them to use and contribute to the worlds' collective knowledge. Recent Human Development Reports utter that richest one percent of the world population owns as much as fifty-seven percent of the resources and income. Therefore the role of technology in creating and generating resources is expected to follow the path whereby inequalities between rich and poor, developed and developing, be minimized. The same is possible, if lessons can be shared and learned from the experienced. However such learning can't be taken as sacrosanct. National scenario needs to be taken into consideration during formulation and execution of the policies pertaining to engineering education. It may not be inappropriate to mention that every policy possesses its strength and weakness as like every technological advancement possesses potential benefits, threats and risks and also possesses widely varying capacities to handle those threats risks. The third world countries, as recent experiences says, becomes the worst sufferers of such risks. Technology in coming days is expected to eradicate the inequalities in absorbing or in preventing the risks of technological development with the properly drawn policy of Engineering Education.

\section{NOTES}

1. Social change is a less accelerated phenomenon compared to technological advancement.

2. The policy through which the developed nations attract the outstanding brains from developed nations and harness them for their own (national) development. As a result, the developing nations face the problem of 'brain-drain'. 
Roy, R.
3. The task stands with NITTTRs where advancement of knowledge is yet in the stage of infancy; in reality, within womb.

4. Browsing over Indian dissertation abstracts reveal the fact.

5. The comment was made by Professor LS Srinath, Professor-Emeritus in a convocation speech in a premier IIT.

\section{SELECTED REFERENCES}

Ahlstrom, G. (1982). Engineers and Industrial Growth, London: Groom Helm.

Arthur, C. (1993). Why Graduates Won't Wear Science, New Scientist, March 27.

Augustine, N. (1994) (chair). Engineering Education for a Changing World, ASEE

Aulich, Sen. T.G. (Chair), (1990) Priorities for Reform in Higher Education, Report of the Senate Standing Committee on Employment, Education and Training, Canberra: Australian Government Publishing Service.

Banerjee and Muley (2007). Engineering Education in India, Draft Final Report. Bombay: IIT.

Beder, S. (1989). Towards a More Representative Engineering Education. International Journal of Applied Engineering Education, vol. 5, no.2, pp 173-182.

Beswick, D., Julian, J., and Macmillan, C. (1988). A national Survey of Engineering Students and Graduates, Centre for the Study of Higher Education, University of Melbourne, Australia.

Bothwick, S. and Murphy, T. (1998). Supply and Demand for Scientists and Engineers, Department of Education, Employment, Training and Youth Affairs, Canberra: Australian Government Printing Service

Braham, J. (1992). The Silence of the Nerds? Machine Design, Volume 64, No 17, p.77.

Cross, H. (1980), Engineers and Ivory Towers, New York: Ayer Company Publishers.

Deans, J. (1999). The Educational Needs of Graduate Mechanical Engineers in New Zealand, European Journal of Engineering Education, Volume 24, No2, June, P.151-162. http://dx.doi.org/10.1080/03043799908923550

Department of Employment, Education and Training (2005). Selected Higher Education Statistics 2004, DEET, Canberra: AGPS.

Department of Employment, Education, Training and Youth Affairs (1998). Selected Higher Education Statistics 1997, DEETYA, Canberra: AGPS

Department of Labour and National Service (1973), Survey of the Australian Engineering Profession1971, Canberra: Australian Government Printing Service.

Diedrich, G. (2000). Private Communication, Hamburg, Germany, July.

Dowell, E., Baum, E., and McTague, J. (1998). The Green Report: Engineering Education for a Changing World, American Society for Engineering Education: http://www.asee.org/ publications/html/green.htm

Ellis, R.A. (1991). Engineering and engineering technology degrees, Engineering Education, P. 34-44.

Finniston, M. Sir (1980) Engineering Our Future. Committee of Inquiry into the Engineering Profession, London: HMSO.

Florman, C.S. (1994). The Existential Pleasures of Engineering, London: Souvenir Press, p.13.

Florman, S.C. (1996). Non-Technical Studies for Engineers: The Challenge of Relevance, European Journal of Engineering Education, Volume 21, No1, p.249-258.

Issues and Ideas in Education (IIE), Volume 1, March 2013 
Glover, I.A., and Herriot, P(1982). Engineering students and manufacturing: Chalk and cheese? Energy World, April, p.8-12.

Goldman,L.S. (2004). Whydowe need a philosophyofengineering: a work in progress. Interdisciplinary Science Reviews, 29 (2), pp.163-176. http://dx.doi.org/10.1179/030801804225012572

Goldman, L.S.(1991). The Social Captivity of Engineering, in Durbin, T.P. (ed) Critical Perspectives on Non-academic Science and Engineering, pp. 121-145, Betlehem: Lehigh University Press.

Gordon, G. (2000). Comparability of postgraduate academic qualification: Some issues, challenges and experiences: Higher Education, v. 40, p. 377-388. http://dx.doi.org/10.1023/A:1004111415962

Goss, E.(1969). 'Change in Technological and Scientific developments and its Impact upon the Occupational Structure', in Perrucci, R., and Gerstl, J. (eds) The Engineers and the Social System, New York: John Wiley and Sons.

Grinter, S. (1955), (chair). Report of the Committee on Evaluation of Engineering Education, Journal of Engineering Education, 46 p.25-60.

Haq, M. S. (1975). Education and Development Strategy in South and South East Asia, Honolulu: East-west Centre.

Hilton, R.,and Lee, I.(1988). Educating Scientists and Engineers, Office of Technology Assessment, United States Congress, OTA Report Brief, Superintendent of Documents, Washington, DC: United States Printing Office, June.

Hotchkiss, E.W. (1935). Social Sciences in Engineering Schools, Journal of Engineering Education, (XXVI), p.94.

Howard, D.(2005). Albert Einstein as a Philosopher of Science. http://www.physicstoday

Huband, L.F. (2007). A Better World Through Engineering. Prism, Summer, p.6.

Hutchinson, A.M., Follman, K.D., Sumpter, M. \& Bodner, M.G. (2006). Factors Influencing the SelfEfficacy Beliefs of First Year Engineering Students, Journal of Engineering Education, January, pp.39-47.

Hutton, P.S., and Gerstl, E.J. (1995). The Effects of Background and Training on Success in Engineering, in Semler, G.E.(ed) The Engineer and Society, London: Institution of Mechanical Engineers, p.142.

Hutton, P.S., and Lawrence, P. (1982). German Engineers: An Anatomy of a Profession, Oxford: Clarendon Press.

India, Government of. (2008).Selected Educational Statistics, MHRD, Department of Planning, monitoring and Statistics division: New Delhi.

Jakobeit, Cord. (1999). 'The World Bank and Human Development', Development and Cooperation, No.6 (Nov/Dec): 4 -5.

Johnson, P.(1996), (chair). Changing the Culture: Engineering Education into the Future, Barton, ACT : Institution of Engineers, Australia

Johnston, C. (1994). Profession moves to convert conservatism to social relevance, Campus Review, November 24-30, p.13.

Larson, M.S. (1979). The Rise of Professionalism: A Sociological Analysis, Berkeley, CA: University of California Press.

Layton, T.E. Jr. (1976). American Ideologies of Science and Engineering, Technology and Culture, 17, No4, p.688-701. http://dx.doi.org/10.2307/3103675 
Roy, R.
Layton, T.E. Jr. [1971], The Revolt of the Engineers: Social Responsibility and the American Engineering Profession, Cleveland: The Press of Cape Western University.

Mann, R.C. (1919). The American Spirit in Education, US Bureau of Education Bulletin, No 30 (1919) p.50.

Mazumder, Tapas. (1998). Economics of Indian Education: The Emerging Policy, and Finance' Asian Development Review, 15(2): 86-130.

Moorehouse, C.E. (1964). Engineering Courses in Australian Universities, The Australian University, 2

Muller, H.D., and Collet, M. (1995.) How to make a Manager out of an Engineer, in Krueger, R.E., and Kulacki, A.T. Proceedings of the Fourth World Conference on Engineering Education, Saint Paul, Minnesota, Vol 3.

National Academy of Engineering [NAE] Activity 7 (2004). The Philosophy of Engineering- defining engineering and the constituent parts; educating engineers and the public on the meaning and impact of engineering.

National Engineers Register (1994), Engineering Manpower in Profile, Washington, DC: National Science Foundation.

National Science Foundation (2004). An Emerging and Critical Problem of the Science and Engineering Labor Force: A Comparison of Science and Engineering Indicators. www.nsf. gov/sbe/srs/nsb0407/stat.htm

Prandy, K.(1965). Professional Employees: A Study of Scientists and Engineers, London: Faber and Faber.

Richards, J. (1992). Poor Image Prevails, Professional Engineering, January 9, Southampton: Mechanical Engineering Publications.

Ritti, R.R.(1971) The Engineer in the Industrial Corporation, New York: Columbia University Press.

Roy, R. et. al. (2006). Attitude of the Working Engineers towards Distance Mode of Instruction. Indian Journal of Open Learning; 15 (3), 225-235.

Sen, Amartya. (2000). Development as Freedom: Oxford University Press. New Delhi.

Shulman, S.L. (2005). If Not Now, When? The Timeliness of Scholarship of the Education of Engineers, Journal of Engineering Education, January, p.11.

Skobrook, S. (2006). The role of pre-entry practices and induction strategies in relation to student retention. Strategy Guide Resource of the PROGRESS Project, University of Hull: http:// www.engsc.ac.uk?downloads/progress/shobrook.pdf

Thulstrup, W.E. (1999). Secondary School - University Interface: Science and Engineering, Global Journal of Engineering Education, Vol 3, 1 p.9-20.

Tilak, J.B.G. (2001): 'Education and Development', Indian Social Science Review, 3 (2): pp. 219-266. New Delhi.

Weingart, P. (1978). The relation between science and technology - a sociological explanation, in Weingart, P., Krohn, W., and Layton, E.T.(eds) Sociology of Sciences Yearbook: The Dynamics of Science and Technology, Dordrecht: D. Reidel

Wilenski, H. (1964). Varieties of Work Experience, in Borrow, H. (ed) Man in a World of Work, Boston: Houghton-Miffin.

Wilenski, H.(1964). The Professionalization of Everyone, American Journal of Sociology, 70.

Willam, W \& Stephen J.G.: Educational Measurement and Testing, Allyn and Bacon Inc, Boston, 1985.

Williams, B. Sir (1988). Review of the Discipline of Engineering, Canberra: AGPS

Issues and Ideas in Education (IIE), Volume 1, March 2013 
Wilson, R. (2005). Projections of Occupations and Qualifications, DfEE \& Institute of Employment Records, Warwick, UK: University of Warwick

Woolnough, B.E. (1991). The Making of Engineers and Scientists, Oxford University, The Department of Educational Studies.

Yates, A. (2000). Discussion Paper on Raising the Status of Engineers, The Institution of Engineers Australia, Sydney.

Zussman, R. (1985). Mechanics of the Middle Class: Work and Politics among American Engineers, Berkely: University of California Press.

Dr Rajarshi Roy possesses to his credit more than hundred papers in various journals of international and national repute including six reference volumes. Way back in 2008, he was offered with professorship in a PG Department of Education in a Government University. Presently he is associated with National Institute of Technical Teachers' Training \& Research, Kolkata and working on policy perspectives on sustainable development.
Thinking Comparative Engineering Education: India and the Rest 